\title{
QUANTITATIVE LIPID COMPOSITION OF IBERIAN PIG MUSCLE AND ADIPOSE TISSUE BY HIGH-PERFORMANCE LIQUID CHROMATOGRAPHY
}

\author{
Javier S. Perona and Valentina Ruiz-Gutierrez* \\ Instituto de la Grasa (CSIC). \\ Av. Padre García Tejero, 4. \\ 41012 Seville (Spain)
}

E-mail: valruiz@cica.es

Running title: Lipid classes of Iberian pig fat by HPLC-ELSD

*Corresponding author

\begin{abstract}
Cholesteryl esters (CE), triacylglycerols (TG), free cholesterol (FC), monoacylglycerols (MG) and phospholipids (PL) were simultaneously determined by high-performance liquid chromatography (HPLC) coupled to a light-scattering detector (ELSD) and in Iberian pig fat from adipose tissue and Masseter muscle. The precision of the HPLC system was excellent, showing RSD values of repeatability lower than $5.27 \%$ for detector response and $0.12 \%$ for retention times. TG were the major lipid class detected, accounting for nearly $80 \%$ in the muscle and $86 \%$ in adipose tissue. The fatty acid compositions of total lipids, TG and PL in the tissues studied were characterized for high concentrations of oleic (18:1, n-9), palmitic (16:0) and stearic (18:0) acids. We conclude that the method reported here is suitable for rapid
\end{abstract}


and precise determination of lipid classes in Iberian pig fat and may be suitable for the analysis of the sensory quality of this and other meat products.

Key words: Iberian pig, lipid classes, HPLC, triacylglycerol, cholesterol

\section{INTRODUCTION}

The sensory quality of meat products from Iberian pigs is determined by the lipid fraction, which is mainly comprised of triacylglycerols (TG), cholesterol (C) and phospholipids (PL). The implications of these lipid classes in meat quality depend on the physical and chemical traits of each class (1). The main volatile compounds participating in flavour are originated from lipid oxidation (2). TG have a small proportion of polyunsaturated fatty acids (PUFA) and therefore are less susceptible to oxidation than PL. However, TG constitute a good matrix for hydrophobic flavour compounds (1). Iberian pigs have higher lipid and TG content in muscles than white pigs reared in industrial conditions as a consequence of a high-fat diet, enriched in acorns and pasture $(3,4)$. The genetically low potential for muscle deposition of these pigs, as long as such a high-fat diet leads to both adipose tissue development and intramuscular fat deposition (1).

The lipid classes content of Iberian pig adipose tissue and muscle have been very rarely analyzed. Habitually, only TG and PL are separated by means of solid phase extraction (SPE) and their fatty acid composition determined by gas chromatography (GC) (5). These and other lipid classes can be analyzed very accurately by HPLC, usually employing normal stationary phases, among which those enriched in hydroxyl groups, the so-called diol columns, have achieved the best results $(6,7)$. The introduction of the evaporative light-scattering detector (ELSD) brought a major advance in the detection of lipid classes by HPLC. Being sensitive just to the mass of vaporized analyte, the ELSD is not limited by the solvent flow rate or 
ambient temperature (8). In addition, it eliminates the need of lipid derivatization, produces a quantitative response and allows the use of chloroform $(8,9)$.

Up to 12 different lipid classes have been simultaneously analyzed using the HPLCELSD system (10). Seppanen-Laakso et al. (7) optimized a HPLC-ELSD method for the quantitation of lipid classes in human plasma. However, to our knowledge, no method has been developed or adapted for the lipid classes analysis of Iberian pig fat by HPLC, which are characterized for an extremely high concentration of TG (1). In the present study, we optimised a method by HPLC, with ELSD, for the quantitative analysis of cholesteryl esters (CE), TG, free cholesterol (FC), monoglycerides (MG) and phospholipids (PL) in Masseter muscle and abdominal adipose tissue of Iberian pig. 


\section{EXPERIMENTAL}

\section{Muscle and adipose tissue sampling}

The protocol for animal handling and experimentation was approved by the Institutional Committee on Investigation in Animals (Universidad de Sevilla, Seville, Spain). Masseter muscle and abdominal adipose tissue were removed from an Iberian pig frown on Montanera diet (mainly acorns and pasture) and raised at an outdoor exploitation. Tissues were placed under vacuum and stored at $-80^{\circ} \mathrm{C}$ until used. $2.1525 \mathrm{~g}$ of adipose tissue and $2.6122 \mathrm{~g}$ of muscle were used for the analyses.

\section{Lipid extraction and fractionation}

Total lipids were extracted following the method of Folch et al. (11), using 2,6-di-tertbutyl-p-cresol (BHT) as antioxidant. An aliquot was collected for the determination of lipid classes by HPLC as described below and was stored until was used at $-80^{\circ} \mathrm{C}$. TG and PL were isolated by SPE diol columns (Supelclean ${ }^{\mathrm{TM}}$ LC-Diol, Supelco, Bellefonte, PA) using hexane/methylene chloride $(9: 1, \mathrm{v} / \mathrm{v})$ as eluent. The eluate was evaporated to dryness under a stream of nitrogen and redissolved in hexane. An aliquot of each lipid class was taken for the analysis of fatty acids by GC.

\section{HPLC system}


A 2690 Alliance liquid chromatograph (Waters, Milford, MA) was used and was computer controlled by the Millenium 34 System (Waters, Milford, USA). The system has an automatic injector incorporated, which allowed injection of variable volumes. Typically, $10 \mu 1$ of lipids, dissolved in chloroform/methanol (2:1, v/v) were injected. Detection was accomplished with a light-scattering detector (DDL31 Eurosep, Ins, Cergy-Pontoise, France). The detector settings were kept constant in all experiments using an evaporation temperature of $40^{\circ} \mathrm{C}$ and nitrogen pressure of 1.5 bar. The separation of lipid classes was carried out on a Lichrosphere column (250 x $4.6 \mathrm{~mm}, 5-\mu \mathrm{m}$ particle size, Merck, Darmstadt, Germany). The column temperature was maintained constant at $30^{\circ} \mathrm{C}$ throughout the experiments. Detailed scheme of the mobile phase composition and gradient elution profile are given in Table 2 . The flow rate was $0.8 \mathrm{ml} / \mathrm{min}$.

\section{Quantification of lipid classes}

Stock solutions containing $2 \mathrm{mg} / \mathrm{ml}$ of CE, TG, DG, FC, MG and PL were prepared in chloroform/methanol $(2: 1, \mathrm{v} / \mathrm{v})$ and used for identification and quantification. In order to calibrate the detector and to establish the capacity factor $\left(\mathrm{k}^{\prime}\right)$ of the system, quintupled runs of six concentrations of these standards $(0.25$ and $2.5 \mathrm{mg} / \mathrm{mL}$ in chloroform/methanol, $2: 1)$ were injected. Equations resulting from regression curves (Figure 1) of these standards were employed for quantification. These injections were also employed to test the repeatability of the method. Adipose tissue and muscle lipids were injected ten times each in the HPLC system to calculate repeatability.

\section{Fatty acid analysis by GC}


Total lipids, TG and PL were transmethylated and the resulting fatty acid methyl esters (FAME) analysed by GC as described by Ruiz-Gutiérrez et al., (12) using a model 5890 series II gas chromatograph (Hewlett-Packard Co, Avondale, USA) equipped with a flame ionisation detector (FID) and a capillary silica column Supelcowax 10 (Sulpelco Co, Bellefonte, USA) of $60 \mathrm{~m}$ length and $0.25 \mathrm{~mm}$ internal diameter.

\section{Chemicals}

The solvents (chloroform, methanol, 2-propanol and hexane) were of HPLC grade (Romil Ltd, Cambridge, UK). Cholesterol oleate, triolein, cholesterol, diolein, monoolein and dipalmitoyl phosphatidylethanolamine (Sigma St. Louis, USA) were used as standards for CR, TG, FC, DG, MG and PL, respectively.

\section{Statistical analysis}

The significance of the differences of the fatty acid composition of TG, PL and total lipids between Masseter muscle and adipose tissue was assessed by the t-test. 


\section{RESULTS AND DISCUSSION}

The organoleptical quality of the Iberian pig-derived products is dependant on their lipid fraction, which serves both as source of volatile compounds after lipid oxidation and as solvent for them (1). Habitually, lipid classes are determined in pig adipose tissue and muscle using different methods for each class. For instance, phosphorus determination is employed for phospholipids analysis (1), HPLC or GC for cholesterol $(13,14)$. Nevertheless, the most prominent analysis employed for lipid determination in pig and pig-derived products is the fatty acid analysis by GC. TG have been determined by colorimetric methods or even from the difference between total lipids and the rest of lipid classes. To our knowledge the only attempt to develop a method for the simultaneous determination of lipid classes in pig tissues was carried out by Fernandez et al. (15). These authors quantified lipid classes in the muscle of DurocxLandrace crossbreeding pigs, but they did not provide data on the precision of their method. The study we present here is therefore the first method developed for the determination of lipid classes in adipose tissue and muscle of Iberian pigs.

In the present study, we achieved the separation of standards of CE, TG, DG, FC, MG and PL in just 24 minutes, (Figure 1), using a ternary solvent system, consisting of hexane, 2propanol and methanol (Table 1). The authors that have separated these lipid classes have before generally employed very complex solvent systems, comprised of mixtures of solvents in binary or ternary gradients $(11,16)$. We employed a ternary elution system but no solvent mixture, simplifying the analysis. The system was extremely precise, showing RSD values for the retention times of the standards of $0.06,0.03,0.07,0.12,0.05$ and 0.03 for CE, TG, DG, FC, MF and PL, respectively. Despite the low selectivity between CE and TG $(\alpha=0.856)$, the 
chromatographic peaks were resolved to the baseline, allowing a good quantification. The use of $100 \%$ hexane in the mobile phase at the beginning of the analysis allowed a rapid elution of the relatively apolar lipid classes (i.e. CE and TG), compromising the resolution of the chromatographic peaks $(7,16)$. When others have developed similar methods, they have tried to solve this drawback by using a complex gradient of 4 solvents but the selectivity of the chromatographic peaks for CE and TG was not improved greatly (17).

The introduction of mass or evaporative light-scattering detector (ELSD) brought a major advance in the detection of lipid classes upon HPLC separation. ELSD, being sensitive just to the mass of vaporized analyte, is not limited by the absorption characteristics of the individual components and/or the nature of the eluents. For this reason it is compatible with gradient elution and volatile solvents do not give baseline drift, as they are removed before detection of the analyte by evaporation. The only requirement is that the compounds to detect must be less volatile than the solvent. However, the ELSD response is different for various lipid classes and the response is dependant upon concentration. Therefore, for accurate quantification it is imperative the use of external standard using individual calibration curves for each compound analyzed (8). In the present study we adjusted calibration curves to linear equations, showing $\mathrm{r}^{2}$ coefficients lower than 0.98 , whereas second-order polynomial curves yielded $\mathrm{r}^{2}$ values very close to 1 , but only for a short range of amount injected. When dealing with a wider range, the responses were better adjusted to polynomial curves $(18,19)$. Christie and Urwin (20) showed linear responses over 10-200 $\mu \mathrm{g}$. However, others have reported curved responses for low (up to $2.5 \mu \mathrm{g}$ ) (21) or high (up to $98 \mu \mathrm{g}$ ) (22) amounts injected. In the present study we injected the standards at amounts as low as $0.25 \mu \mathrm{g}$ and as high as $10 \mu \mathrm{g}$, which is 40 times higher. 
The main lipid class found in both tissues studied (muscle and adipose tissue) was TG, although it was significantly higher in the adipose tissue (7.62 $\mathrm{g}$ vs $8.23 \mathrm{~g}$ per $100 \mathrm{~g}$ ), with a RSD value for TG very close to $2 \%$ (Table 3 ). The free cholesterol content was similar in both tissues studied, but lower amounts of cholesteryl esters and phospholipids were found in the adipose tissue. The TG and PL contents in muscle and adipose tissue are in agreement with the contents reported by other authors for Iberian and other pigs. Gandemer (23) reported TG and PL values for muscle from pigs of different European areas. The values for TG and PL contents were established in $8.6 \pm 2.9$ and $0.72 \pm 0.09 \mathrm{~g} / 100 \mathrm{~g}$, which are very similar to the values proposed by Tejeda et al. (1). There is scarce information on the lipid classes composition of Iberian pig adipose tissue. The cholesterol content of pig muscle and adipose tissue has been very rarely reported. By means of HPLC, Fernandez et al., (15) determined the cholesterol content in pig intramuscular fat finding $0.02 \mathrm{~g} / 100 \mathrm{~g}$. Bragagnolo \& RodriguezAmaya (13) reported cholesterol concentrations in pig meat and backfat, finding values close to $0.05 \mathrm{~g} / 100 \mathrm{~g}$ and to $0.10 \mathrm{~g} / 100 \mathrm{~g}$, respectively. The cholesterol content found in our study resulted to be higher than in those mentioned, probably due to de use of a different breed of pig. For the first time we have quantified the cholesteryl ester composition of adipose tissue and muscle of Iberian pig. The content of CE in adipose tissue was significantly lower than in muscle $(\mathrm{p}<0.001)$. In contrast, the TG concentration was higher $(\mathrm{p}<0.01)$.

In addition to the lipid classes composition we determined the fatty acid profile of total lipids, TG and PL (Tables 4-6). The analysis of fatty acids by GC is widely employed as a criterion to differentiate the qualities of the feed types given to the pigs in the fattening state (5). As expected, the main fatty acid found in the tissues studied was oleic acid, accounting 
for nearly $50 \%$ in TG and PL. The amount of this fatty acid was significantly higher in adipose tissue but the difference was greater in the PL fraction. These results are in agreement with those reported before. Garcia-Olmo et al. (5) recently performed a mini collaborative study on the precision of GC for the determination of fatty acids in Iberian pig, concluding that the method is accurate a reliable.

Total lipids in the muscle presented a higher concentration of saturated fatty acids (SFA), due to higher amounts of palmitic (16:0) and stearic (18:0) acids. Both TG and PL contributed to these effects, since such differences were observed in both lipid classes. In the TG fraction, linoleic acid (18:2, n-6) presented a higher amount in the adipose tissue than in the muscle. In contrast the concentration of this fatty acid was significantly augmented in the PL fraction of the muscle. It is noteworthy that the concentration of arachidonic acid (20:4, n-6), metabolically derived from linoleic acid, in the PL fraction of the muscle was dramatically higher in the muscle than in the adipose tissue.

In conclusion, the method reported here proved to be a rapid and reliable tool for the quantification of lipid classes in muscle and adipose tissue of Iberian pig, with good repeatability and accuracy. This method, along with the fatty acid methyl ester analysis of the fat would be useful for the analysis of the sensory quality of Iberian pig fat, but also other meat products.

\section{ACKNOWLEDGEMENTS}


This work was financed by grants from Comisión Interministerial de Ciencia y Tecnología (CICYT) (AGL2002-00195) and Junta de Andalucia (CAO01-002) and an I3P contract to JSP (European Social Funds).

\section{REFERENCES}

1. Tejeda, J.F.; Gandemer, G.; Antequera, T.; Viau, M.; García, C. Lipid traits of muscles as related to genotype and fattening diet in Iberian pigs: total intramuscular lipids and triacylglycerols. Meat Sci 2002, 60,357-363.

2. García C.; Berdagué J.J.; Antequera T.; López-Bote C.; Córdoba J.J.; Ventanas J. Volatile compounds of dry cured Iberian ham. Food Chem. 2002, 41, 23-32.

3. Lopez-Bote, C.J. Sustained Utilization of the Iberian Pig Breed. Meat Sci 1998, 49, S17-S27.

4. Cameron, N.D.; Enser, M.; Nute, G.R.; Whittington, F.M.; Penman, J.C.; Fisken, A.C.; Perry, A.M. Genotype with nutrition interaction on fatty acid composition of intramuscular fat and the relationship with flavour of pig meat Meat Sci. 2000 55, 187-195.

5. García-Olmo, J.; De Pedro, E.; Garrido, A.; Paredes, A.; Sanabria, C.; Santolalla; M. Determination of the precision of the fatty acid analysis of Iberian pig fat by gas chromatography. Results of a mini collaborative study. Meat Sci. 2002, 60,103-109.

6. Stith, B.J.; Hall, J.; Ayres, P.; Waggoner, L.; Moore, J.D.; Shaw, W.A. Quantification of major classes of Xenopus phospholipids by high performance liquid chromatography with evaporative light scattering detection. J. Lipid Res. 2000, 419,1448-1454.

7. Seppanen-Laakso, T.; Laakso, I.; Vanhanen, H.; Kiviranta, K.; Lehtimaki, T.; Hiltunen, R. Major human plasma lipid classes determined by quantitative high-performance liquid chromatography, their variation and associations with phospholipid fatty acids. $J$. Chromatogr. B. 2001, 7542,437-445. 
8. Christie,W.W. Detectors for HPLC of lipids with special reference to evaporative lightscattering detection. In Advances in Lipid Methodology - One. Edited by W.W. Christie, Oily Press, Ayr.pp. 1992. 239-271.

9. Becart, J.; Chavalier, C.; Biesse J.P. Quantitative analysis of phospholipids by HPLC with light scattering detector: application to raw materials for cosmetic use. J. High Resol. Chromatogr. 1990, 13, 126-129.

11. Folch J.; Less M.; Sloan-Stanley G.H. A simple method for the isolation and purification of total lipids from the animal tissues. J. Biol. Chem. 1957, 33, 497-509.

11. Schaefer, A.; Kuchler, T.; Simat, T.J.; Steinhart, H. Migration of lubricants from food packagings. Screening for lipid classes and quantitative estimation using normal-phase liquid chromatographic separation with evaporative light scattering detection. J. Chromatogr. 2003, $10171,107-116$.

12. Ruiz-Gutiérrez, V.; Montero, E.; Villar, J. Determination of fatty acid and triacylglycerol composition of human adipose tissue. J Chromatogr. 1992, 581,171-178.

13. Bragagnolo N.; Rodriguez-Amaya D.B. Simultaneous determination of total lipid, cholesterol and fatty acids in meat and backfat of suckling and adult pigs. Food Chem. 2002 $79,255-260$.

14. Petron, M.J.; Garcia-Regueiro, J.A.; Martin, L.; Muriel, E.; Antequera, T. Identification and quantification of cholesterol and cholesterol oxidation products in different types of Iberian hams. J. Agr.Food Chem. 2003, 5119, 5786-5791.

15. Fernandez X.; Monin G.; Talmant A.; Mourot J.; Lebret B. Influence of intramuscular fat content on the quality of pig meat - 1. Composition of the lipid fraction and sensory characteristics of m. longissimus lumborum. Meat Sci 1999, 53, 59-65.

16. Silversand, C.; Haux C. Improved high-performance liquid chromatographic method for the separation and quantification of lipid classes: application to fish lipids. J. Chromatogr. B. 1997, 7031, 7-14. 
17. Homan, R.; Anderson, M.K. Rapid separation and quantitation of combined neutral and polar lipid classes by high-performance liquid chromatography and evaporative lightscattering mass detection. J. Chromatogr. B. 1998, 7081, 21-26.

18. Perona, J.S.; Ruiz-Gutierrez, V. Simultaneous determination of molecular species of monoacylglycerols, diacylglycerols and triacylglycerols in human very-low-density lipoproteins by reversed-phase liquid chromatography. J.Chromatogr. B, 2003, 7851, 89-99.

19. Juaneda, P.; Rocquelin, G.; Astorg, P.O. Separation and quantification of heart and liver phospholipid classes by high-performance liquid chromatography using a new lightscattering detector. Lipids 1990, 2511, 756-759.

20. Christie W.W.; Urwin R.A. Separation of lipid classes from plant tissues by highperformance liquid chromatography on chemically bonded stationary phases. J High Resol. Chromatogr. 1995 18, 97-100.

21. Kong, L.; Li, X.; Zou, H.; Wang, H.; Mao, X.; Zhang, Q.; Ni J. Analysis of terpene compounds in Cimicifuga foetida L. by reversed-phase high-performance liquid chromatography with evaporative light scattering detection. J. Chromatogr. A 2001, 9361, 111-118.

22. Olsson, N.U.; Harding, A.J.; Harper, C.; Salem N. Jr. High-performance liquid chromatography method with light-scattering detection for measurements of lipid class composition: analysis of brains from alcoholics. J. Chromatogr. B. 1996, 6812, 213-218.

23. Gandemer G. Lipids in muscles and adipose tissues, changes during processing and sensory properties of meat products. Meat Sci. 2002, 62, 309-321. 
Figure 1. Calibration curves for lipid standards. A series of dilutions of a solution containing a mixture of lipid standards was injected $(10 \mu \mathrm{L})$ in quintuplicates. The mean values of the resulting peak areas were calculated and plotted against the amounts injected for each lipid class. The lines represent the best fit of the data to a second-order equation. CE; cholesteryl esters; TG, triacylglycerols; FC, free cholesterol; MG, monoacylglycerols; PE: phosphatidylethanolmine.

Figure 2. HPLC-chromatogram of Masseter muscle lipid classes of Iberian pig. $10 \mu \mathrm{L}$ of lipids were injected as described in the text. CE, cholesteryl esters; TG, triacylglycerols; FC, free cholesterol; PL, phospholipids.

Figure 3. HPLC-chromatogram of adipose tissue lipid classes of Iberian pig. $10 \mu \mathrm{L}$ of lipids were injected as described in the text. CE, cholesteryl esters; TG, triacylglycerols; FC, free cholesterol; PL, phospholipids. 
Table 1. Ternary gradient mobile phase composition

$\begin{array}{cccc}\text { Time (min) } & \mathrm{A}(\%) & \mathrm{B}(\%) & \mathrm{C}(\%) \\ 0 & 100 & 0 & 0.0 \\ 3 & 100 & 3.0 & 0.0 \\ 17 & 90.0 & 10.0 & 0.0 \\ 22 & 0.0 & 40.0 & 60.0 \\ 28 & 0.0 & 40.0 & 60.0\end{array}$

A: hexane; B: 2-propanol; C: methanol. 
Table 2. Repeatability of detector response and lipid retention times ( $2.5 \mu \mathrm{g}$ each),

injected 5 times.

\begin{tabular}{|c|c|c|c|c|c|c|}
\hline \multirow[t]{2}{*}{ Lipid Class } & \multicolumn{3}{|c|}{ Peak area $\times 10^{4}$} & \multicolumn{3}{|c|}{$\begin{array}{l}\text { Retention } \\
\text { time (min) }\end{array}$} \\
\hline & Mean & SEM & $\begin{array}{l}\text { RSD } \\
(\%)\end{array}$ & Mean & SEM & $\begin{array}{l}\text { RSD } \\
(\%)\end{array}$ \\
\hline $\mathrm{CE}$ & 15.11 & 0.58 & 3.85 & 4.11 & 0.00 & 0.06 \\
\hline TG & 6.90 & 0.63 & 5.21 & 4.80 & 0.00 & 0.03 \\
\hline DG & 3.17 & 0.14 & 4.57 & 14.52 & 0.01 & 0.07 \\
\hline $\mathrm{FC}$ & 11.81 & 0.61 & 5.27 & 16.08 & 0.02 & 0.12 \\
\hline MG & 2.45 & 0.03 & 1.04 & 22.21 & 0.01 & 0.05 \\
\hline PL & 5.92 & 0.14 & 2.02 & 23.43 & 0.01 & 0.03 \\
\hline
\end{tabular}


Table 3. Lipid classes composition (g/100g) of Masseter muscle and abdominal adipose tissue of Iberian pig

\begin{tabular}{ccccccc} 
Lipid & \multicolumn{5}{c}{ Masseter } & \multicolumn{5}{c}{ Adipose tissue } \\
Class & Mean & SEM & RSD & Mean & SEM & RSD \\
CE & 0.66 & 0.03 & 4.85 & 0.16 & 0.01 & 3.99 \\
TG & 7.62 & 0.16 & 2.04 & 8.23 & 0.12 & 1.43 \\
FC & 0.27 & 0.01 & 3.90 & 0.73 & 0.05 & 6.24 \\
PL & 1.05 & 0.06 & 5.62 & 0.46 & 0.02 & 3.36 \\
\hline CE, cholesteryl esters; TG, triacylglycerols; FC, free cholesterol; MG, \\
\multicolumn{7}{l}{ monoacylglycerols; PL, phospholipids. }
\end{tabular}


Table 4. Fatty acid composition of total lipids in the Masseter muscle and abdominal adipose tissue of Iberian pig.

\begin{tabular}{|c|c|c|c|c|}
\hline & \multicolumn{2}{|c|}{ Masseter } & \multicolumn{2}{|c|}{ Adipose Tissue } \\
\hline & Mean & SD & Mean & SD \\
\hline 10:0 & 0.02 & 0.00 & 0.02 & 0.00 \\
\hline $12: 0$ & 0.02 & 0.00 & 0.02 & 0.00 \\
\hline $14: 0$ & 1.19 & 0.02 & 1.21 & 0.02 \\
\hline $16: 0$ & 23.56 & 0.18 & $21.22 *$ & 0.17 \\
\hline $16: 1,(n-9)$ & 0.27 & 0.00 & 0.28 & 0.01 \\
\hline $16: 1,(n-7)$ & 2.65 & 0.09 & 2.15 & 0.03 \\
\hline $16: 1,(n-5)$ & 0.18 & 0.01 & $0.27 *$ & 0.01 \\
\hline $16: 2,(n-7)$ & 0.15 & 0.01 & $0.25 *$ & 0.01 \\
\hline 18:0 & 10.34 & 0.03 & $8.57 *$ & 0.04 \\
\hline $18: 1,(n-9 t)$ & 0.23 & 0.01 & $0.46^{*}$ & 0.01 \\
\hline $18: 1,(n-9)$ & 48.26 & 0.12 & $50.61 *$ & 0.12 \\
\hline $18: 1,(n-7)$ & 4.93 & 0.32 & 4.81 & 0.09 \\
\hline $18: 2,(n-6)$ & 6.00 & 0.02 & $7.91 *$ & 0.15 \\
\hline $18: 3,(n-3)$ & 0.15 & 0.01 & 0.10 & 0.01 \\
\hline 20:0 & 1.28 & 0.02 & $1.49 *$ & 0.02 \\
\hline $20: 1,(n-9)$ & 0.24 & 0.01 & $0.35^{*}$ & 0.01 \\
\hline $20: 2,(n-6)$ & 0.07 & 0.01 & 0.06 & 0.01 \\
\hline $20: 3,(n-6)$ & 0.07 & 0.01 & 0.10 & 0.01 \\
\hline $20: 4,(n-6)$ & 0.42 & 0.01 & $0.16^{*}$ & 0.01 \\
\hline SFA & 36.40 & 0.21 & $32.52 *$ & 0.17 \\
\hline MUFA & 56.76 & 0.22 & $58.93 *$ & 0.15 \\
\hline PUFA & 6.86 & 0.05 & $8.58^{*}$ & 0.16 \\
\hline
\end{tabular}

*:p<0.001 vs Masseter muscle 
Table 5. Fatty acid composition of TG in the Masseter muscle and abdominal adipose

\section{tissue of Iberian pig}

\begin{tabular}{|c|c|c|c|c|}
\hline & \multicolumn{2}{|c|}{ Masseter } & \multicolumn{2}{|c|}{ Adipose Tissue } \\
\hline & Mean & $\mathrm{SD}$ & Mean & $\mathrm{SD}$ \\
\hline 10:0 & 0.05 & 0.00 & 0.04 & 0.00 \\
\hline $12: 0$ & 0.07 & 0.00 & 0.07 & 0.00 \\
\hline $14: 0$ & 1.24 & 0.01 & 1.31 & 0.02 \\
\hline $16: 0$ & 23.47 & 0.02 & $21.7 *$ & 0.04 \\
\hline $16: 1,(n-9)$ & 0.30 & 0.01 & 0.30 & 0.01 \\
\hline $16: 1,(n-7)$ & 2.26 & 0.02 & 2.2 & 0.05 \\
\hline $16: 1,(n-5)$ & 0.20 & 0.01 & 0.27 & 0.01 \\
\hline $16: 2,(n-7)$ & 0.16 & 0.01 & $0.27 *$ & 0.02 \\
\hline 18:0 & 10.55 & 0.02 & $8.64 *$ & 0.04 \\
\hline $18: 1,(n-9 t)$ & 0.26 & 0.01 & $0.45^{*}$ & 0.01 \\
\hline $18: 1,(n-9)$ & 49.01 & 0.06 & $50.55^{*}$ & 0.08 \\
\hline $18: 1,(n-7)$ & 3.59 & 0.04 & $4.02 *$ & 0.02 \\
\hline $18: 2,(n-6)$ & 6.66 & 0.02 & $7.88 *$ & 0.02 \\
\hline $18: 3,(n-3)$ & 0.17 & 0.00 & $0.11^{*}$ & 0.01 \\
\hline 20:0 & 1.47 & 0.01 & 1.53 & 0.03 \\
\hline $20: 1,(n-9)$ & 0.28 & 0.01 & 0.34 & 0.01 \\
\hline $20: 2,(n-6)$ & 0.04 & 0.00 & 0.06 & 0.01 \\
\hline $20: 3,(n-6)$ & 0.07 & 0.00 & 0.09 & 0.01 \\
\hline $20: 4,(n-6)$ & 0.13 & 0.00 & 0.13 & 0.00 \\
\hline SFA & 36.84 & 0.03 & $33.30 *$ & 0.09 \\
\hline MUFA & 55.91 & 0.06 & $58.14 *$ & 0.09 \\
\hline PUFA & 7.23 & 0.02 & $8.54 *$ & 0.02 \\
\hline
\end{tabular}

*:p<0.001 vs Masseter muscle 
Table 6. Fatty acid composition of FL in the Masseter muscle and abdominal adipose tissue of Iberian pig

\begin{tabular}{|c|c|c|c|c|}
\hline & \multicolumn{2}{|c|}{ Masseter } & \multicolumn{2}{|c|}{ Adipose Tissue } \\
\hline & Mean & $\mathrm{SD}$ & Mean & $\mathrm{SD}$ \\
\hline $14: 0$ & 1.13 & 0.07 & 1.27 & 0.02 \\
\hline $14: 1,(n-5)$ & 0.80 & 0.03 & $0.25^{*}$ & 0.04 \\
\hline 16:0 & 21.63 & 0.06 & $20.39 *$ & 0.11 \\
\hline 16:1, (n-9) & 0.48 & 0.05 & $0.36^{*}$ & 0.02 \\
\hline $16: 1,(n-7)$ & 2.13 & 0.05 & 2.29 & 0.01 \\
\hline $16: 1,(n-5)$ & 0.29 & 0.16 & 0.24 & 0.01 \\
\hline $16: 2,(n-7)$ & 0.66 & 0.10 & $0.37 *$ & 0.03 \\
\hline 18:0 & 9.18 & 0.13 & $7.99 *$ & 0.02 \\
\hline $18: 1,(n-9 t)$ & 0.60 & 0.08 & $0.42 *$ & 0.03 \\
\hline $18: 1,(n-9)$ & 45.30 & 0.16 & $50.70^{*}$ & 0.15 \\
\hline $18: 1,(n-7)$ & 3.74 & 0.08 & $4.42 *$ & 0.13 \\
\hline $18: 2,(n-6)$ & 10.58 & 0.12 & $9.05^{*}$ & 0.07 \\
\hline $20: 0$ & 1.44 & 0.05 & 1.58 & 0.05 \\
\hline 20:1, (n-9) & 0.40 & 0.02 & 0.34 & 0.01 \\
\hline $20: 4,(n-6)$ & 1.57 & 0.10 & $0.33^{*}$ & 0.04 \\
\hline SFA & 33.39 & 0.30 & $31.23^{*}$ & 0.19 \\
\hline MUFA & 53.74 & 0.62 & $59.01 *$ & 0.40 \\
\hline PUFA & 12.81 & 0.32 & $9.74 *$ & 0.14 \\
\hline
\end{tabular}



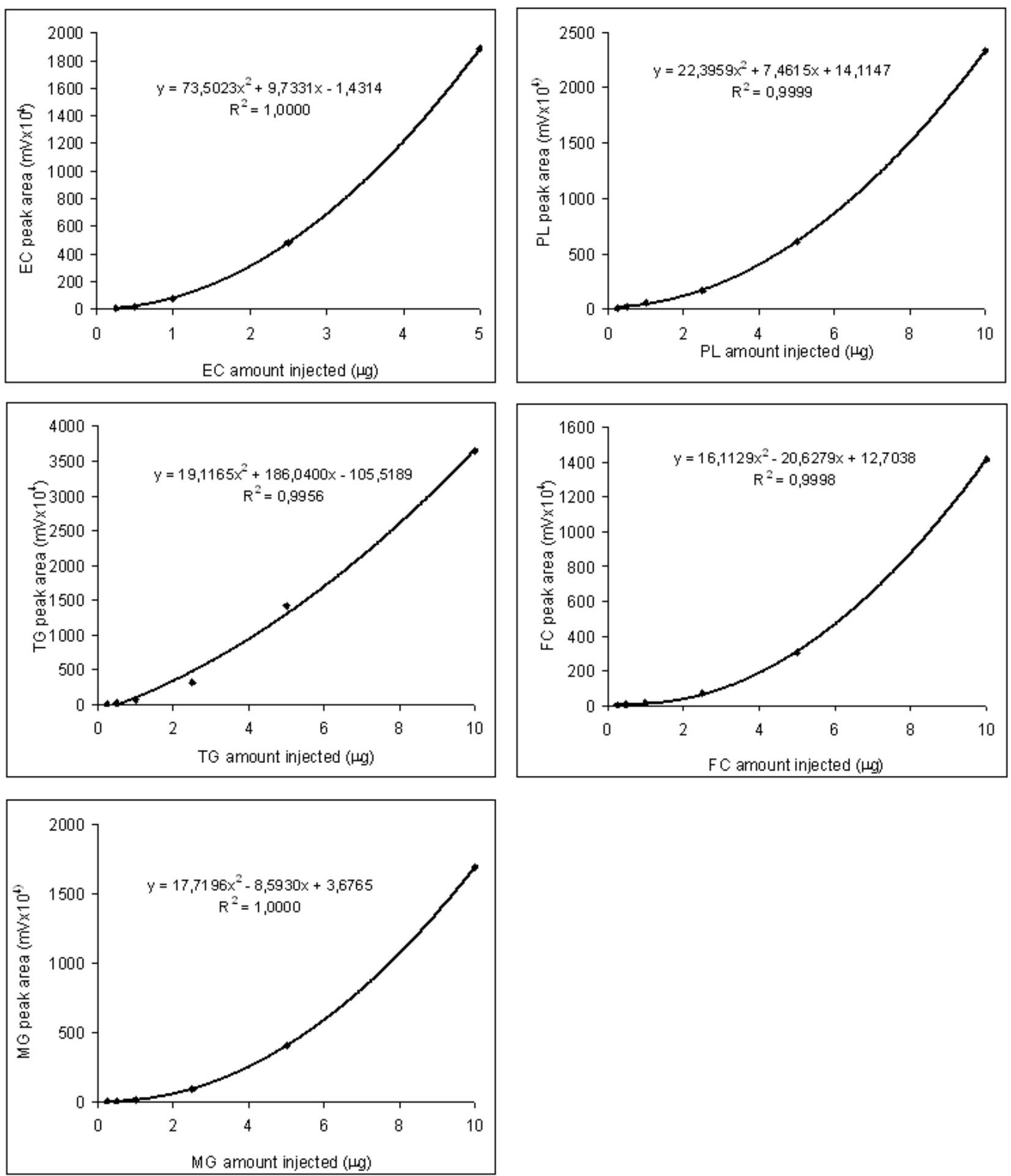


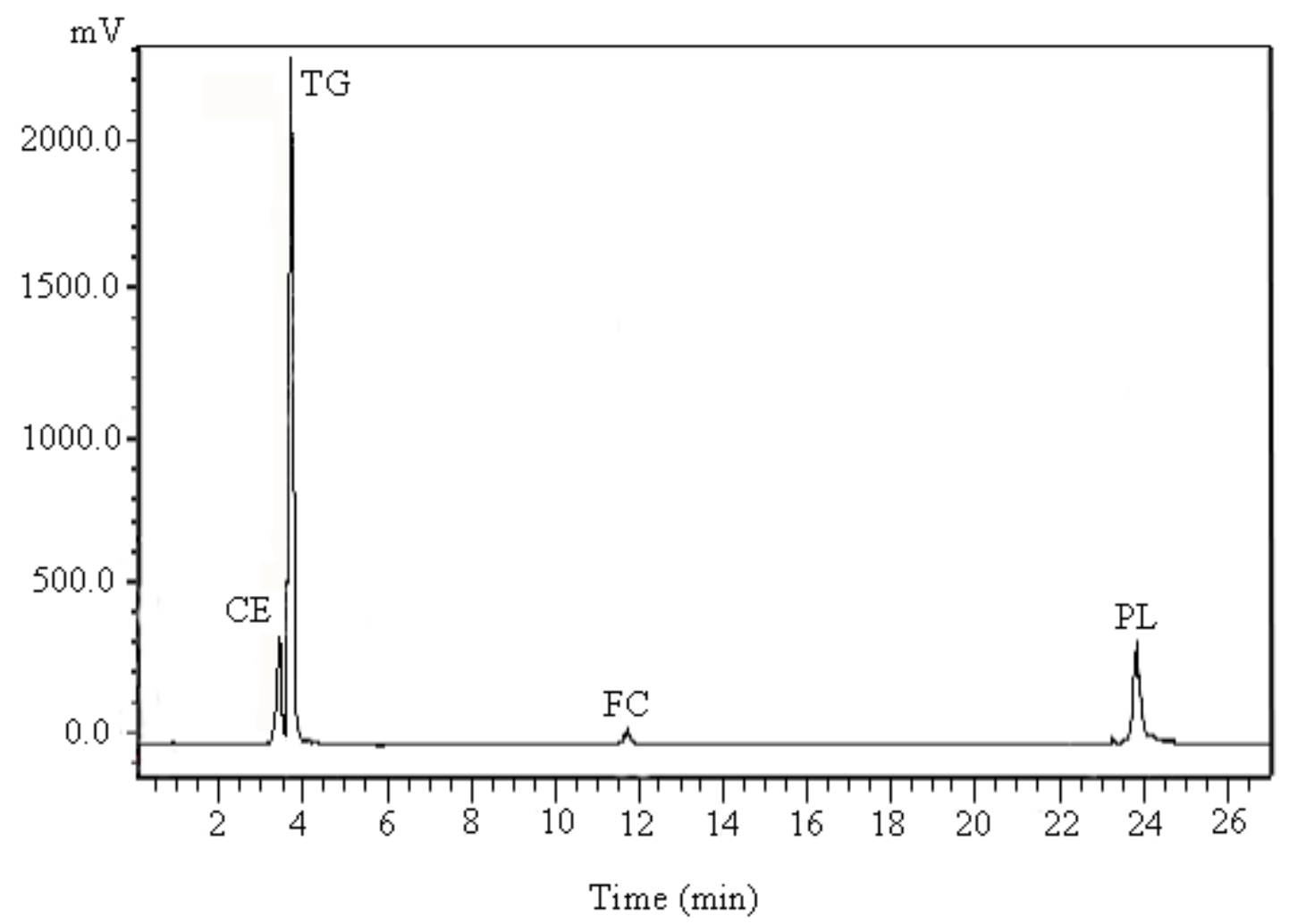




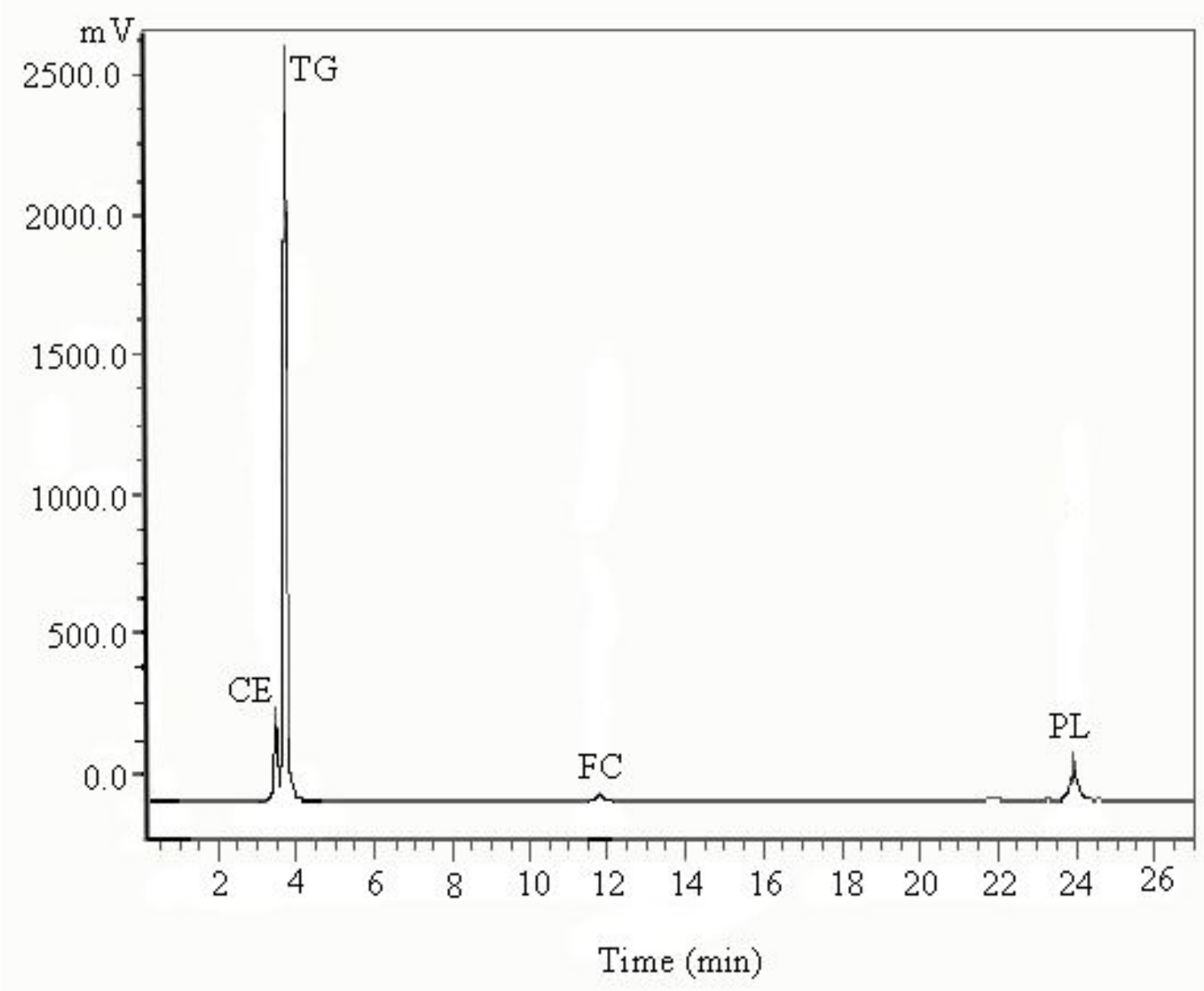

